\title{
LA POLIITICA Y LA DEMOCRACIA COMO CREACIONES IMAGINARIAS: DE LOS GRIEGOS A NOSOTROS
}

\author{
POLITICS AND DEMOCRACY AS IMAGINARY \\ CREATIONS: OF THE GREEKS TO US
}

\section{HAROLD VALENCIA LÓPEZ*}

\section{RESUMEN}

Nuestro trabajo está articulado en tres partes: En la primera, empleando el marco categorial de la teoría de la imaginación de Cornelius Castoriadis, dilucidamos en qué sentido la política y la democracia son creaciones imaginarias, cómo entender la imaginación y el elemento imaginario que hay en la creación humana, qué son las significaciones imaginarias sociales y qué función cumplen para la cohesión social. En la segunda parte tematizamos los aspectos que nos permiten diferenciar el imaginario político griego respecto del imaginario político moderno, mostrando en qué sentido el régimen democrático es la realización política del proyecto de autonomía. En la parte final, mostramos cómo los aspectos sustantivos de la democracia están escamoteados en las concepciones procedimentalistas e instrumentalistas de la misma. Concluimos proponiendo nuestra idea de una educación para la democracia como teoría crítica.

Palabras clave: Política, democracia, significaciones imaginarias, instrumentalismo.

\section{ABSTRACT}

This article is developed in three parts. In the first, using the categorial framework of the theory of the imagination by Cornelius Castoriadis, we elucidate the sense in which politics and democracy are imaginary creations, how to understand the imagination and the imaginary element that there is in human creation, what the social imaginary

* Filósofo, Magíster y Doctor en Filosofía. Especialista en Arbitraje, conciliación y resolución de conflictos de la Universidad de Cartagena. Profesor Titular del Programa de filosofía de la Universidad de Cartagena. Ex decano de la Facultad de Ciencias Humanas de la Universidad de Cartagena, Colombia. Director del grupo de investigación en filosofía política y social "Civitas". Correo electrónico: hvalencial@unicartagena.edu.co 
meanings are and what function they fulfill for social cohesion. In the second part, we focus on the aspects that allow us to differentiate the Greek political imaginary with respect to the modern political imaginary, showing in what sense the democratic regime is the political realization of the project of autonomy. In the final part, we show how the substantial aspects of democracy are concealed in its very proceduralist and instrumentalist conceptions. We conclude by proposing our idea of education for democracy as critical theory.

Keywords: Policy, democracy, imaginary significations, instrumentalism.

Recibido: 11.06.14. Aceptado: 02.10.14.

I

T A POLÍtica Y LA DEMOCRACIA son creaciones imaginarias del pueblo griego antiguo (siglos VI a IV a.C.), porque son actividades radicalmente nuevas que ningún pueblo antes de ellos había producido y que no son abstraídas de la experiencia, ni sacadas de la naturaleza, ni mucho menos deducidas de un sistema lógico, ni tampoco se pueden simplificar a unas causas últimas sociales, históricas, económicas o funcionales. Son como la Quinta sinfonía de Beethoven, como el Guernica de Pablo Picasso, como Cien años de soledad de García Márquez, una creación. Antes de ellas no existía nada similar. En este sentido compartimos la tesis de Cornelius Castoriadis ${ }^{1}$ que sostiene que la historia humana, y por tanto las diversas formas de sociedad, son esencialmente el resultado de la creación imaginaria de los pueblos, esto es, cada sociedad crea un mundo (griego, egipcio, feudal, moderno, burgués, musulmán, Caribe, etc.) a partir de un elemento que posee el ser humano en singular y los colectivos en general: el elemento imaginario.

Pero, ¿qué entender por imaginación, por imaginario?, ¿en qué aspectos podríamos distinguir el imaginario político griego del moderno?

\footnotetext{
${ }^{1}$ Cornelius Castoriadis (Constantinopla, 1922 - París, 1997): filósofo, psicoanalista, militante político, pensador social, economista. Fue cofundador del grupo-revista Socialismo o Barbarie (que se publicó entre 1948 y 1967), desde el que inició una crítica radical de la URSS en particular, y del marxismo en general, defendiendo el autogobierno de los trabajadores y el proyecto de un sujeto reflexivo y deliberante y de una sociedad autónoma. Esto -entre otras cosas- desembocó en un nuevo modo de pensamiento, que halló expresión en buena medida en el movimiento estudiantil del Mayo Francés de 1968, y se expandió a otros lugares del globo. El pensamiento de Castoriadis ha sido uno de los aportes más importantes a la elucidación ilimitada sobre el ser humano, la sociedad, lo instituido, en la última década del siglo XX, abarcando de modo profundamente interrelacionado campos como el de la política, el psicoanálisis, la filosofía, la economía, etc., según su método de encrucijadas del laberinto. Su libro más significativo es La institución imaginaria de la sociedad. Véase: Valencia López (2012, pp. 253-260).
} 
Imaginación creadora, imaginario social instituyente, e imaginación radical, son conceptos íntimamente asociados, pero que presentan algunas diferencias entre sí. En la base está la idea de imaginación que propone Castoriadis (1989), quien, cuando habla de imaginación, la está considerando como creadora. Y que postula como nombre de la misma, para su corpus teórico, el de imaginario radical. Este imaginario radical tiene un componente individual y un componente social. Por una parte, se presenta en la psique singular como imaginación radical creadora de un magma ${ }^{2}$ de representaciones, afectos, deseos (RADS), pues en la psique existe una capacidad de producir un flujo ilimitado de representaciones indominable, desfuncionalizado. La imaginación tiene capacidad constituyente tanto a nivel del psiquismo individual como a nivel de la sociedad. Es radical en tanto es fuente de creación. Esta noción se diferencia de toda idea de la imaginación como señuelo, reflejo, engaño, lo especular³. La imaginación radical en el colectivo toma el nombre y la forma de imaginario social instituyente. El imaginario social instituyente crea un mundo de sentido, que a su vez crea a los sujetos que lo habitan. Sujetos en tanto que judíos, incas, ciudadanos de la Pólis, colombianos, etc. La imaginación en la sociedad es creación de un mundo de significaciones imaginarias sociales (SIS) (Castoriadis, 1989 , pp. 283 y ss.; 2002, pp. 187 y ss.).

Las significaciones imaginarias sociales son creaciones libres de la colectividad anónima; aunque existen sobre ellas constricciones internas, externas, históricas e intrínsecas, son sociales, porque las comparten los miembros de una colectividad. Son también imaginarias, porque no se pueden reducir, ni se pueden deducir de referentes "reales" o "racionales"; la "rea-

\footnotetext{
${ }^{2}$ Magma: Concepto fundamental del pensamiento de Castoriadis, mediante el cual propone una nueva forma de pensar el ser de lo psíquico, de lo histórico-social, que rebase las categorías de la lógica del principio de identidad y de no contradicción, pues como el magma de un volcán, lo psíquico es un flujo permanente de representaciones, deseos, intenciones, afectos (RADS). El ser de lo histórico social es un magma de significaciones imaginarias sociales (SIS). El modo de ser de la psique como el de lo histórico-social es a la manera de un magma. La teoría de la relatividad, la física cuántica, el modo de ser del inconsciente, son tesis que apoyan la idea castoridiana del Ser como indeterminado, que permiten pensar en la creación, que remiten al caos. Esto permite, en la dilucidación castoridiana de la sociedad y la historia, sustentar-que lejos de haber leyes, como la del desarrollo de las fuerzas productivas como motor de la historia (marxismo), o entender a la misma como estadios o despliegues del ser, o del Espíritu (Hegel) - que la historia es la creación y destrucción de Magmas de significaciones imaginarias sociales. Véase: Castoriadis (1989, pp. 288 y ss.), Castoriadis (1993), Franco (2003).

${ }^{3}$ Castoriadis rastrea cómo en el pensamiento de Occidente existen pensadores como Aristóteles primero, y Kant luego, que, muy cerca de considerar la imaginación como creación radical, terminan no explicitando esta forma de pensar. Véase: Castoriadis, "El descubrimiento de la imaginación”. En: Los dominios del hombre: Las encrucijadas del laberinto (2005a, pp. 149-176).
} 
lidad" y la "racionalidad" son sus productos, instituidos de modo diferente en cada época. No son "racionales", no son lógicos, no dependen de una deducción, ni son "reales". No son sacadas, "abstraídas" del mundo físico, sino que son creaciones de la imaginación colectiva y anónima que mantiene cohesionada y unida la sociedad al crear un sentido y un significado para la misma. Y son significaciones, esto es, no exactamente "conceptos" o "representaciones", sino el cemento de la vida social que mantiene unidas las ideas, las representaciones, los actos, etc. Ejemplos de significaciones imaginarias sociales son: los dioses, los espíritus, los mitos, los tótem, los tabúes, la familia, la soberanía, la ley, el ciudadano, la justicia, el Estado, la mercancía, el capital, el interés, la realidad, etc.

Las significaciones imaginarias sociales cumplen una triple función dentro de una sociedad: 1 . Constituyen el conjunto de representaciones mediante las cuales un grupo constituye un mundo, se sitúa en él, se autorrepresenta. 2. Definen las funciones de los miembros de un grupo, el qué hacer: adorar a dios, incrementar el desarrollo de las fuerzas productivas, buscar la fama, etc. 3. Determinan el tipo de afectos predominantes en una sociedad. Por ejemplo, la fe cristiana en la sociedad católica; el ansia de consumir, la novedad por lo nuevo en el capitalismo contemporáneo.

Estas significaciones en cada contexto socio-histórico son introyectadas en los individuos a través de agentes socializadores como la familia, la escuela, las instituciones políticas, económicas, religiosas, etc.

Ahora bien, toda sociedad crea un poder instituyente que en la mayoría de los casos permanece velado para los individuos. Este poder instituyente adopta una doble forma: lo político y la política.

Lo político significa la dimensión del poder, es decir, la instancia o las instancias instituidas, que pueden emitir mandatos con autoridad, que toman decisiones, que dirimen conflictos, y que, al menos, deben incluir siempre, de forma explícita, lo que denominamos un poder judicial y un poder de gobierno (Castoriadis, 1998c, p. 219). Lo político "preserva" la sociedad y no reposa fundamentalmente en la coerción, sino en la interiorización que hacen los individuos de las significaciones imaginarias sociales que les introyectan los agentes sociales. En ese sentido, todas las sociedades han tenido lo político (egipcios, aztecas, colombianos, etc.), pero no necesariamente la política, pues la política, como la creó el imaginario griego, es la actividad lucida, reflexiva, explícita, que cuestiona lo instituido buscando su transformación. La política rompe una falsa unidad, quiebra un orden que se supone natural, "normal". La política se da cuando irrumpe la diferencia que ha estado oculta y lo público se "ensancha" y se hace verda- 
deramente público. La política en el sentido propuesto es proyecto de autonomía: actividad colectiva reflexionada y lúcida que busca la institución global de la sociedad como tal. Lo propio de la política estaría constituido por las nuevas formas de subjetivación que irrumpen. La política no se da sino en ocasiones especiales, pues la política no es la práctica de todos los días, sino una irrupción frente a un orden dado para ponerlo en cuestión, $y$, en el mismo momento en que lo cuestiona, es porque considera que puede instituirse otro; por lo tanto que no hay una determinación fatal de lo instituido.

Lo instituido, lo político, puede estancar a la política en la medida en que cierra la posibilidad de irrupción de nuevas formas de subjetivación políticas, en la medida en que clausura y no permite el cuestionamiento.

En la autoconservación de lo político y en la mayoría de las sociedades históricamente dadas se le ha enseñado a los hombres que el poder instituyente proviene de fuerzas extrasociales: Dios, reyes, hijos de los dioses, linaje, fuerzas sobrenaturales. En esa institución heterónoma está prohibido preguntar, hay que obedecer y someterse a los poderes de facto. Generalmente los individuos en las sociedades heterónomas piensan y actúan de acuerdo al conjunto social; psíquica y lingüísticamente no están preparados para cuestionar. Son sociedades cerradas, clausuradas. En el mundo hebreo del Antiguo Testamento no cabe la pregunta sobre qué es el ser, si Dios mismo es el ser, o qué es verdad, qué es justicia, si Dios mismo es todo. La interrogación está cerrada. Se impone el discurso del otro y el "discurso del Otro" generalmente se concreta como heteronomía social.

La grandeza del imaginario griego, entre otras, está en que rompe con la institución heterónoma y crea el proyecto de autonomía, es decir, la actividad consciente y explicita que lucha para que las instituciones, las leyes, los reguladores sociales, sean el resultado de la actividad consciente y lúcida del poder instituyente de los ciudadanos.

Pero, ¿qué significa autonomía en la esfera política? Una sociedad autónoma es, como primera aproximación, la que niega la existencia de un fundamento extrasocial a la ley y extrae consecuencias de ello. La originalidad e improbabilidad de la autonomía consiste en la aparición de un ser histórico que cuestiona su propia ley de existencia y de una sociedad que cuestiona su propia institución, su representación del mundo, sus significaciones imaginarias sociales y que es capaz de dotarse de sus propias leyes, entendiendo que es eso lo que está haciendo. Una sociedad autónoma exige individuos autónomos, es decir, individuos reflexivos, críticos, capaces de ser conscientes de sus propias significaciones imaginarias. En el proyecto 
de sociedad autónoma el poder de crear significación no le pertenece a una instancia sobrenatural sino a los ciudadanos. Lo que hace incompatible esta concepción con el liberalismo y la democracia representativa es su anulación de cualquier dispositivo trascendental que imponga un contenido o un límite a la labor de autoinstitución política. Dios, los antepasados, la superstición, pero también la Razón del sistema hegeliano, la hipóstasis del mercado o la figuración de una idea sustantiva de la humanidad, no pueden dar cuenta u orientar el proceso instituyente del colectivo anónimo que es la sociedad.

Ahora bien, la forma política que adquiere el proyecto de autonomía es el régimen democrático. La creación democrática suprime toda fuente trascendente de la significación. La democracia es el régimen político de autoinstitución y autolimitación resultado de la acción de los ciudadanos y en el que siempre están abiertas las preguntas por la libertad, la igualdad, la justicia, etc.

II

Pero, ¿cuáles son los rasgos más relevantes del imaginario político griego que nos permiten contrastarlo y diferenciarlo del imaginario político moderno ${ }^{4}$ ? Destacamos, entre otros, los siguientes:

1. Relación de la colectividad con el poder. El poder para los griegos tiene su génesis en el poder directo constituyente e instituyente de los ciudadanos y no, como para los modernos, en la idea de representación política. Si se considera en la práctica, la participación política de los antiguos es limitada (no todos están incluidos en la categoría de ciudadanos). En los modernos, aunque en teoría hay mayor universalización de la ciudadanía, la participación es restringida. Hay un conflicto entre la dimensión universalista del imaginario político y otra dimensión del imaginario político moderno: el Estado-Nación, en cuanto el Estado-Nación reconoce ciertos derechos sólo a sus nacionales.

\footnotetext{
${ }^{4}$ Estamos empleando el concepto "moderno" en el sentido del proyecto de introducir en todos los ámbitos de la actividad humana la razón (Descartes), esto es, todo tipo de problemas debería ser resuelto apelando no a la tradición, a la autoridad, sino a una instancia autónoma del individuo, al tiempo supuestamente universal, como lo es la razón. La humanidad, al obrar según leyes de la razón, progresaría hacia la libertad, la prosperidad y la felicidad.
} 
2. En el imaginario político griego la esfera de lo público es asunto de ciudadanos, de opinión, de deliberación, distinto a la tendencia en la modernidad de dejar los asuntos públicos a expertos, técnicos, "comisiones de sabios". En el mundo antiguo hay expertos, pero su ámbito de competencia es la técne.

3. En el imaginario político griego no hay una separación tajante, como en la modernidad, entre la sociedad y el Estado, sino el poder político lo ejerce la sociedad. En la modernidad el Estado es un aparato separado de la colectividad y tiende a ser centralizado.

4. En el mundo antiguo no existe la ilusión constitucional en el sentido que la limitación del poder no está dada por un "documento", sino que la limitación es autolimitación dada en la paideía que forma al ciudadano.

5. En el imaginario moderno se considera que la división de poderes es garantía del equilibrio y control de los poderes públicos, pero prima y absorbe en muchas ocasiones el poder gubernativo a los otros poderes.

6. En el mundo antiguo hay una relación entre democracia, mortalidad, limitación. En el origen griego de la democracia, como enfatiza Castoriadis (2005a; 1998b, pp. 157-180), lo fundamental es la contingencia, la mortalidad de toda actividad humana (hombre y mortal son sinónimos). Sobre estas cuestiones, precisamente, trabaja la tragedia y este es su mensaje: no olvides que eres mortal. Mortalidad habitada por la hybris, que no es el pecado, sino la desmesura. El pecado supone fronteras bien demarcadas, mientras que lo propio de la hybris es que no hay frontera bien trazada, por lo cual en cualquier momento se puede caer en ella, y los dioses o los hombres o las propias circunstancias intervendrán para producir el castigo correspondiente. Cuando Castoriadis (1998b) describe la cultura actual, señala que ésta es una época donde predomina el rechazo de toda noción de mortalidad. Sucede que se ha perdido el sentido trágico que en su momento señalaran los griegos, el límite que debe ponerse a la desmesura, a la hybris. La democracia, como pensamiento de los límites, implica un régimen basado en la libertad, y por lo tanto, en el riesgo. En ella el pueblo puede hacer cualquier cosa, pero debe saber que no debe hacer cualquier cosa. La democracia como pensamiento político es inevitablemente atea. Sus límites, "garantías", no hacen recurrencia a la existencia de un dios, de un ser trascendente y superior. Para la democracia no hay más que una "ga- 
rantía" relativa. La menos contingente de todas se encuentra en la paideía, la educación de los ciudadanos, en la formación de individuos que han interiorizado al tiempo la necesidad de la ley y la posibilidad de ponerla en tela de juicio.

7. Precisamente, se constituye en un punto arquimédico del imaginario griego de la democracia lo que llamaron la paideia, la educación del individuo humano. Los griegos comprendieron que el ser humano, el ciudadano, no nace, sino que se forma en el proceso de humanización, de socialización; que el individuo sin la comunidad no puede ser, de ahí la importancia de qué tipo de educación se le dé a ese nuevo ser que viene al mundo. En la modernidad hay un énfasis en el individuo desprendido de la comunidad; en la autarquía de la mónada individual, hay un refugio en los goces particulares, en el ámbito privado.

8. El Ethos político dominante entre los atenienses es su sinceridad: "La ley que se impone es la del más fuerte" (Castoriadis, 1998b, p. 169). El derecho sólo existe entre iguales. En la modernidad se dice una cosa y se hace otra, herencia de la Iglesia medieval: "todos somos iguales", tal vez ante los ojos de Dios, pero no en la terrenalidad.

9. En los antiguos subyace la ontología de caos/cosmos, fhysis/nómos. En la ontología moderna subyace la idea de progreso, vamos ascendiendo a una "tierra prometida", vamos hacia mayores grados de felicidad y poder. Desarrollo en los griegos es la llegada de una substancia a su plenitud siempre existiendo un límite. Desarrollo en los modernos es expansión ilimitada del supuesto dominio racional, más producción, más crecimiento económico, más dominio sobre la naturaleza.

Ahora bien, con el decaimiento de la democracia griega, con los hechos históricos que marcaron la antigüedad romana y la edad media en Occidente, el proyecto de autonomía, de autoinstitución lúcida y explícita de la sociedad sufre un eclipse del siglo III a.C. al siglo XII. En la modernidad con la génesis de las ciudades, el ascenso de la burguesía, las Revoluciones burguesas (Americana, Francesa), la Revolución Rusa, los movimientos emancipatorios latinoamericanos, vuelve a haber un nuevo impulso al proyecto de autonomía. Las teorías del contrato social con el cuestionamiento de los principios tradicionales de legitimación del poder político forman parte de dicho proyecto de autonomía. También forman parte de dicho 
proyecto emancipatorio, las luchas obreras, la lucha de las mujeres en el siglo XX, de los jóvenes, mayo del 68, la lucha de los negros, los movimientos de África y Latinoamérica contra el racismo, contra los neocolonialismos, los movimientos ecologistas, los movimientos que luchan por el reconocimiento de la diversidad sexual.

Sin embargo, con el ascenso del neoliberalismo en los años 80 del siglo pasado y la noción de desarrollo generada desde ahí, centrada en el imaginario de la ilimitación y en crecimiento económico, el proyecto de autonomía entró en un nuevo eclipse y el proyecto de "racionalización capitalista", de la "sociedad como mercado", se ha erigido como proyecto hegemónico, produciendo despolitización creciente de la sociedad, competencia voraz, privatización de lo público, fragmentación social. Fragmentación que no permite tejer comunidad sino que genera "ciudadanos sin brújula y sociedades a la deriva".

En este contexto y luego de la caída del Muro de Berlín (9 de noviembre de 1989), las denominadas "democracias occidentales" con los Estados Unidos a la cabeza salieron a cantar victoria como el mejor de los mundos posibles, pues desde tal perspectiva quedaba la disyunción entre los regímenes occidentales o el totalitarismo izquierdista encarnado en la extinta Unión Soviética. Las preguntas a plantear, entre otras, son: ¿¿cuál democracia quedó?, ¿puede ser democrático un régimen en donde el poder económico y político se concentra en unos pocos y no se distribuye?, ¿ en qué país ejerce el poder el pueblo?, ¿quiénes toman las decisiones fundamentales que afectan las vidas de los ciudadanos?

La democracia en un sentido sustantivo supone la igualdad en el reparto del poder y en las posibilidades de participación en el proceso de toma de decisión política. Esto es imposible cuando, como está sucediendo en las sociedades del capitalismo globalizado, los grupos financieros o burocracias empresariales controlan los centros de un enorme poder económico que se traduce inmediatamente en poder político. La igualdad sustantiva que requiere una democracia y las formas de ciudadanía son más que una igualdad ante la ley. Esa igualdad se resume, no en el hecho de otorgar "derechos" iguales pasivos, sino en la participación general activa en los asuntos públicos. Para que las voces de los distintos grupos de la sociedad puedan ser escuchadas democráticamente, se requiere no sólo "suspender" formalmente las desigualdades reales, sino igualdad social sustantiva, pues la deliberación de los interlocutores en espacios discursivos asignados como si fueran iguales socialmente, cuando dichos espacios están situados en realidad dentro de un contexto social penetrado por relaciones estruc- 
turales de dominación, subordinación y marcada desigualdad, se convierte posible en teoría, pero una quimera en la práctica. Como lo consideraba Rousseau (1988), la democracia es el régimen político que requiere una sociedad donde no haya gente tan pobre que se tenga que vender y gente tan rica que pueda comprar a los otros.

\section{A MANERA DE CONCLUSIÓN}

Entendemos democracia no en su sentido instrumental de movilizar periódicamente y convocar a los ciudadanos a unas elecciones, hechas casi siempre en condiciones de una marcada desigualdad, para elegir gobernantes y representantes, sino en su sentido sustantivo: participación, distribución de poder, distribución económica, alternación en el poder. Sin participación ciudadana en la constitución de lo público no es posible la democracia y sin democracia la posibilidad de resolver pacíficamente los conflictos que se presentan en la convivencia humana se ve seriamente comprometida, pues precisamente la democracia, en uno de sus aspectos, es la búsqueda por regular las relaciones sociales de forma comunicativa, a través de la confrontación de opiniones, argumentos, puntos de vista, constituyendo instituciones que sean el resultado de la libre y autónoma participación de los ciudadanos y no de poderes autoritarios amparados en la fuerza, la tradición, lo sobrenatural o la exclusión económica, educativa, de género o de cualquier otra índole. Pero, la democracia y el ciudadano, como se explicita en el proyecto de paideía griego, no nacen sino que se hacen, no surgen por generación espontánea, no se nace siendo democrático, sino que es necesario forjar ciudadanos(as), educarlos en las significaciones y en las prácticas democráticas, de tal manera que es necesaria una educación para la democracia, pero dicha educación no se puede reducir a unos manuales y cartillas de instrucción cívica, sino que educar para la democracia debe significar hacer teoría crítica de la sociedad, entendida ésta no en el sentido de la crítica idealista de la razón pura, sino como una crítica materialista a través de la cual se hagan conscientes los antagonismos sobre los cuales se erige la sociedad actual, desmontando ideologías, criticando condiciones reales de vida, desenmascarando los refinamientos de la "racionalidad instrumental" y de la historia oficial. La autonomía que debe promover no debe ser la abstracta de la mónada liberal, ajena a la sociedad, a la comunidad, sino vinculada a ella a través de la formación de ciudadanos(as) que tienen como principio y actitud, más que legitimar un saber, una verdad, 
un poder, hacer uso de la capacidad de pensar por cuenta propia, criticar lo evidente, resistir lo que irracionalmente se ampara bajo el autoritarismo, dinamizar el pensamiento para permitirle permanecer abierto al cambio, concebir el conocimiento y la verdad no como lo dado, sino como en constante proceso de construcción.

De ahí que una educación para la democracia deba enseñar a cuestionar las condiciones sociales, tanto intelectuales como materiales que producen y mantienen la heteronomía; cuestionamiento que debe poner en entredicho el poder concentrado en unas cuantas manos, las jerarquías autoritarias, la ideología mistificante de la guerra, y donde la democracia no quede reducida a movilizar periódicamente y convocar a los ciudadanos a unas elecciones en las que se materializan intereses muy contrarios a los de las grandes mayorías, sino que signifique, en su sentido sustantivo: participación, distribución de poder, distribución económica, reconocimiento y respeto por diversas opciones de vida, así como elucidación imaginativa de nuevas posibilidades de convivencia humana.

\section{REFERENCIAS}

Castoriadis, C. (1989). La institución imaginaria de la sociedad. Vol II. El imaginario social y la sociedad. Barcelona: Tusquets Editores.

Castoriadis, C. (1993). El mundo fragmentado. (Encrucijadas del laberinto III). Buenos Aires: Editorial Altamira.

Castoriadis, C. (1998a). El ascenso de la insignificancia. Madrid: Editorial Cátedra.

Castoriadis, C. (1998b). “Imaginario político griego y moderno”. En: El ascenso de la insignificancia. Madrid: Editorial Cátedra, pp. 157-180.

Castoriadis, C. (1998c). "La democracia como procedimiento y como régimen". En: El ascenso de la insignificancia. Madrid: Editorial Cátedra, pp. 218-238.

Castoriadis, C. (2002). Figuras de lo pensable (Las encrucijadas del laberinto VI). México: Fondo de Cultura Económica.

Castoriadis, C. (2005a). "La pólis griega y la creación de la democracia". En: Los dominios del hombre: las encrucijadas del laberinto. Barcelona: Editorial Gedisa.

Castoriadis, C. (2005b). Los dominios del hombre: las encrucijadas del laberinto (cuarta reimpresión). Barcelona: Editorial Gedisa.

Franco, Y. (2003). Magma. Cornelius Castoriadis: psicoanálisis, filosofía, política. Buenos Aires: Editorial Biblos.

Rousseau, J. J. (1988). El contrato social. Madrid: Tecnos.

Valencia López, H. (2012). Teoría crítica y acción política: De Sigmund Freud a Cornelius Castoriadis. Bogotá: Grupo Editorial Ibáñez. 